\title{
A Pilot Study of "Peer Navigators" to Promote Uptake of HIV Testing, Care and Treatment Among Street-Connected Children and Youth in Eldoret, Kenya
}

\author{
Pooja Shah ${ }^{1} \cdot$ Mia Kibel $^{2}$ - David Ayuku ${ }^{3} \cdot$ Regina Lobun $^{1} \cdot$ John Ayieko $^{1} \cdot$ Alfred Keter $^{1} \cdot$ Allan Kamanda ${ }^{4}$. \\ Dominic Makori ${ }^{1}$. Collins Khaemba ${ }^{1}$. Anthony Ngeresa ${ }^{1} \cdot$ Lonnie Embleton $^{5} \cdot$ Katherine MacDonald $^{6}$. \\ Edith Apondi ${ }^{4} \cdot$ Paula Braitstein ${ }^{1,2,7}$
}

Published online: 29 September 2018

(c) The Author(s) 2018

\begin{abstract}
Research suggests a burden of HIV among street-connected youth (SCY) in Kenya. We piloted the use of peer navigators (PNs), individuals of mixed HIV serostatus and with direct experience of being street-connected, to link SCY to HIV testing and care. From January 2015 to October 2017, PNs engaged 781 SCY (585 male, 196 female), median age 16 (IQR 13-20). At initial encounter, 52 (6.6\%) were known HIV-positive and 647 (88.8\%) agreed to HIV testing. Overall, 63/781 (8.1\%) SCY engaged in this program were HIV-positive; $4.6 \%$ males and $18.4 \%$ females $(\mathrm{p}<0.001)$. Of those HIV-positive, 48 (82.8\%) initiated ART. As of October 2017, 35 (60.3\%) of the HIV-positive SCY were alive and in care. The pilot suggests that PNs were successful in promoting HIV testing, linkage to care and ART initiation. More research is needed to evaluate how to improve ART adherence, viral suppression and retention in care in this population.
\end{abstract}

Keywords Peer support $\cdot$ HIV $\cdot$ Youth $\cdot$ Homeless $\cdot$ Africa

\section{Introduction}

Adolescents and youth face particular challenges in accessing services for HIV testing, treatment, and care [1]. Between 2005 and 2012, while the number of AIDS-related

Paula Braitstein

pbraitstein@gmail.com

1 Academic Model Providing Access to Healthcare (AMPATH), Eldoret, Kenya

2 Department of Epidemiology, Dalla Lana School of Public Health, University of Toronto, 155 College Street, 5th Floor, Toronto, ON M5T 3M7, Canada

3 Department of Behavioral Sciences, School of Medicine, College of Health Sciences, Moi University, Eldoret, Kenya

4 Moi Teaching and Referral Hospital, Eldoret, Kenya

5 Faculty of Medicine, Institute of Medical Science, University of Toronto, Toronto, Canada

6 Department of Pediatrics, School of Medicine, Indiana University, Indianapolis, USA

7 Department of Medicine, School of Medicine, College of Health Sciences, Moi University, Eldoret, Kenya deaths fell by $30 \%$ globally, HIV-related mortality among adolescents increased by 50\% [1]. Youth aged 15-24 currently account for $37 \%$ of all new HIV infections in SubSaharan Africa (SSA) [2, 3]. HIV testing is the main entry point into treatment and care for people living with HIV, but rates of testing are still inadequate [4]. In Kenya, only half of adolescents aged 15-19 have ever been tested for HIV, though among those aged $20-24,92 \%$ of females and $67 \%$ of males have been tested for HIV. Fewer than 50\% of adolescents who are HIV-positive are on antiretroviral treatment (ART), and the number retained in care is unclear [5]. ART initiation and retention in care remain prominent challenges in this population $[6,7]$.

Current targets from The Joint United Nations Programme on HIV/AIDS (UNAIDS) state that by the year $2020,90 \%$ of people living with HIV should know their status, $90 \%$ of them should be receiving ART, and $90 \%$ of those on ART should have an undetectable viral load [3]. In Kenya, adolescent health policies aim to reduce new HIV infections by $40 \%$, and HIV-related deaths by $20 \%$. They suggest increasing availability of adolescent-friendly provider-initiated testing and counselling (PITC) and having dedicated services for adolescents to improve retention in 
treatment and care $[5,8,9]$. Testing for HIV and engaging individuals in care is particularly challenging for vulnerable populations such as street youth, as they are often hard to reach, require time to establish trust, and are generally highly mobile and relatively marginalized. [10].

Street-connected children and youth (SCY) spend the majority of their time living and working on the streets. For these individuals, the street is a central reference point, playing a significant role in their daily lives [11]. Data on HIV seroprevalence among SCY in low- and middle-income countries are sparse, but studies in Kenya suggest that high HIV prevalence among SCY $[12,13]$ exceeds that of other adolescents in the country. In Eldoret, Kenya, we found a HIV prevalence of $6 \%$ overall and $15 \%$ among females in a study of 120 SCY aged 12-21 [13]. In Kisumu, Kenya, HIV prevalence among street boys was reported to be $4.1 \%$ [12], but this study included no females. In contrast, HIV prevalence among Kenyan adolescents aged $15-25$ is $2.1 \%$ [5]. Additionally, a study on the causes of death of SCY in Eldoret found that HIV was the underlying cause in $37 \%$ of 100 documented deaths, including 59\% of the 34 females [14]. SCY are at high risk of substance use, sexually transmitted infections, unwanted pregnancies, and physical, sexual, psychological, and economic exploitation and violence $[13,15-21]$. They are generally sexually active and likely to engage in high-risk sexual activity, increasing their risks of acquiring HIV [18, 20, 22-27]. Therefore the most common modes of transmission among SCY are probably heterosexual intercourse and sexual violence [12, 28-30]. In addition to the high-risk environment and burden of HIV, SCY experience barriers in accessing care and services due to their marginalization, stigmatization by community and healthcare providers, and high levels of mobility [31, 32].

Interventions involving peers have been used to improve engagement in care in hard-to-reach populations and may overcome many of the barriers faced by the SCY community [33]. A systematic review conducted by Genberg et al. found some effect of peer interventions in improving linkage and retention, but reported mixed findings on ART adherence, viral suppression, and mortality. Peers who are employed to improve outcomes related to HIV are generally seropositive and receiving treatment themselves. Due to their lived experiences, peers can create a shared social identity and engage individuals in HIV prevention, care and treatment interventions through education, offering support, and providing referrals as needed [34]. Peer navigators (PNs) can also assist HIV-positive individuals in overcoming logistical difficulties in accessing services as well as maintaining engagement in care [35]. Given the burden of HIV discovered in SCY in Eldoret, Kenya, we sought to pilot and evaluate the use of PNs to promote uptake of HIV testing, initiation of treatment and retention in care among an observational cohort of SCY in Eldoret, Kenya.

\section{Methods}

\section{Study Setting}

Uasin Gishu County (UG) is one of 47 counties in Kenya. According to the most recent census, the total population of UG stood at 894,179 , of whom $41.5 \%$ were aged 14 years or under [36]. Eldoret city, the administrative capital of UG, has a population of 289,380 [37]. Located approximately $350 \mathrm{~km}$ north-west of Nairobi, it is home to Moi University, Moi Teaching and Referral Hospital (MTRH), and the Academic Model Providing Access to Healthcare (AMPATH), a large PEPFAR-funded HIV care and treatment program described elsewhere and headquartered at MTRH in Eldoret [38, 39].

\section{The Peer Navigator Program}

The PN program was launched as a care initiative in response to the HIV epidemic identified among SCY in Eldoret. Two PN positions, one male and one female, were advertised through AMPATH, and the successful candidates were employed from January 2015. A PN was initially defined as a person living with HIV and aged between 18-24 years, who had greater than 1 year of recent experience being street-connected. Sometime after the program started, it was discovered that one was actually HIV-negative. We quickly realized the advantage of having PNs of mixed serostatus (one positive, one negative) in an attempt to increase inclusivity and reduce HIVrelated stigma of the PNs or PN program. The PNs were required to be individuals known by the street community, who knew where and how to reach SCY, and had literacy and numeracy skills to Standard/Grade 4 level. The PN position required individuals to be able to conduct community outreach and follow-up individuals over time. The job description explicitly stated that the purpose of the position was to increase linkage to HIV testing and treatment for the SCY population, and to offer education and support on an ad hoc basis to SCY in Eldoret about HIV and related issues. The program was launched in January 2015 after sensitization and mobilization through community meetings known locally as 'mabaraza' [40], traditional community assemblies, group and individual discussions with SCY and other opinion leaders in the community. The initial PN training took place over 5 days and was comprised of extensive multi-disciplinary training by AMPATH clinicians for the PNs on HIV/AIDS prevention, treatment and care, reproductive health, counselling, documentation, as well as navigation through the AMPATH HIV linkage and treatment process. This was followed by 
intensive mentoring and supervision by the social worker. On-going supervision, on-the-job training, and training courses by AMPATH clinicians on reproductive health and ART were provided for the duration of the program. The PNs were based at the adolescent HIV and reproductive health clinic at MTRH.

\section{Field Engagement and Procedures}

SCY primarily reside in specific locations on the street (known locally as 'barracks'). The PNs undertook extensive outreach and sensitization at these locations to establish rapport and build trust with SCY. This was aided by a preexisting relationship between the research team and the SCY community in Eldoret [41, 42]. The Youth Charter in Kenya defines adolescents as individuals aged between 15 and 30 years of age $[43,44]$. For this program, the PNs engaged male and female SCY who were defined as individuals aged $<30$ years who either (a) spent the majority of both days and nights on the street and had limited-to-no parental/guardian contact or (b) spent a portion or majority of their time on the street and had a parent/guardian/caregiver who they returned to at night. Individuals older than 29 were able to receive services but were not included in the analysis. SCY were recruited to the program regardless of their HIV status or current enrolment in care. The female PN focused outreach on locations where female SCY were known to frequent to ensure representation of this especially hard to reach population, as the female SCY were more comfortable interacting with a female PN. As time went on, SCY of all ages became comfortable interacting with both the male and female PNs. SCY interested in engaging with the PN, whether HIV status was known or not, either arrived at the clinic by themselves, or were accompanied by the PNs from town for their initial encounter or at a subsequent follow-up encounter. An encounter was defined as a meeting with the PN where data were collected using the PN encounter form. Engagement into the program was on a continuous basis, with PNs vistiing the barracks multiple times a week throughout the program duration. SCY who initially declined to participate were free to engage with the PN program when they chose.

At an initial encounter, the PN completed an initial encounter data collection form, discussed HIV prevention and offered condoms, assessed HIV status, and, if appropriate, offered HIV counselling and linkage to HIV testing services at AMPATH by Ministry of Health certified HIV counsellors. Those who tested negative were encouraged to return for a general follow-up encounter every 6 months. During each follow-up they were asked whether they had tested for HIV elsewhere since the last encounter. SCY who disclosed their HIV-positive status at their initial or followup encounter were not re-tested unless they requested it. Individuals who tested HIV-positive were offered monthly
HIV care encounters with the PN, were asked about engagement in HIV care and were linked (or re-linked) to care at AMPATH, where they were encouraged to initiate ART and attend regular appointments with the AMPATH healthcare providers. During these monthly care encounters the PNs offered to accompany the SCY from town to the AMPATH clinicians. They also completed a brief encounter form collecting any change in sociodemographic information as well as engagement in HIV services and reasons for not taking ART if applicable. The PNs supported linkage and engagement in HIV services by making SCY feel comfortable as they were in the presence of peers, assisting them with scheduling and reminding them about clinic appointments, providing emotional support and information, as well as navigation and accompaniment through the process of the appointment, e.g. seeing different clinicians in different buildings. Follow-up of those who were HIV-positive was monitored using a diary and automated reminders from the AMPATH Medical Records System (AMRS). For those who were not diagnosed with HIV, follow-up was monitored by the PNs asking individuals when they had last been tested during their visits to the barracks. The PNs referred SCY to HIV-related and other services as needed. HIV testing, ART and follow-up appointments were provided free of charge as part of the AMPATH HIV program. A waiver was obtained from MTRH for all fees and charges related to care and treatment for many non-HIV services including hospitalization if necessary.

\section{Sources of Data}

This study utilized routinely collected clinical care data from the PN program as well as the AMRS. At each encounter, the PNs interviewed SCY privately and completed structured initial, general follow-up, or care encounter forms. Sociodemographic information, living situation, female reproductive health, general health issues, HIV testing and uptake of care, and referrals were collected at each time point.

Sociodemographic variables included age, gender, location, ethnic group, living situation including sleeping location (in a shared shelter, on the street on a veranda or by a kiosk, in a house, or at the barracks/base) and who they stay with at night (with parents, other family, spouse, boyfriend, girlfriend, alone, or other). Data on female reproductive health included current and previous pregnancy status, if pregnant antenatal care attendance, and whether they stay with their own or someone else's children. SCY were also asked about common symptoms including those of sexually transmitted infections (STIs), cough, fever, and tuberculosis diagnosis, symptoms, and treatment. Information collected on HIV testing included whether they had ever been tested for HIV, if they knew their status, were willing to get an HIV test during that encounter, and result of the test. Those who 
knew their HIV-positive status or who newly tested HIVpositive were asked whether they had ever been to, were currently in, or were willing to go for HIV care. Information on willingness to work with a PN, ART use, and disclosure of HIV status were also collected for individuals who were HIV positive.

\section{Data Analysis}

Primary outcomes for this evaluation were uptake of HIV testing, initiation of ART, and retention in care. Retention in care was defined as having attended a clinic visit within 90 days of the expected follow-up date. Individuals who did not attend within the 90 days were defined as lost-to-followup (LTFU). Data collected were entered into EpiInfo (version 6), and exported into STATA.12 and R for analysis. Individuals over 29 years of age were excluded from analysis. Categorical variables were summarized using frequencies and corresponding percentages, and compared using the Chi square test or Fisher's exact test. Continuous variables were summarized using mean/standard deviation or median/ interquartile range, and compared using the Student's t-test or Mann-Whitney U test. The analysis was stratified by sex, and infants perinatally exposed to HIV were excluded from the analysis of HIV outcome variables. Trends prior to and after ART initiation were compared graphically. Time to ART initiation and time to LTFU was studied using Kaplan Meier survival function and compared by care enrolment category (pre-PN or PN). Follow-up time was defined as days from enrolment with PN to the last AMPATH HIV care clinic visit date prior to the closure of the database for analysis.

\section{Results}

From January 2015 to October 2017, the PNs engaged a total of 817 individuals from the street community in Eldoret. Of these, 781 were aged 29 and below, and 36 were aged 30 and above (these individuals were excluded from further analyses). The sociodemographic characteristics of participants are shown in Table 1. The median age of those included in the analyses was $16(\mathrm{IQR} 13-20)$, with $51.3 \%(\mathrm{n}=401)$ aged between $15-24$ years. A quarter (25.1\%) were female. On average, males were younger than females (median 15, IQR 13-19 vs. 18.5, IQR 14-23, p < 0.001). Most males lived on
Table 1 Background characteristics and living situation of eligible SCY

\begin{tabular}{|c|c|c|c|c|}
\hline Variable & $\begin{array}{l}\text { Total } \\
\mathrm{N}=781\end{array}$ & $\begin{array}{l}\text { Male } \\
\mathrm{N}=585(74.9)\end{array}$ & $\begin{array}{l}\text { Female } \\
\mathrm{N}=196(25.1)\end{array}$ & $P$ value \\
\hline \multicolumn{5}{|l|}{ Age } \\
\hline$<5$ & $16(2.1)$ & $4(0.7)$ & $12(6.1)$ & $<0.001$ \\
\hline $5-9$ & $26(3.3)$ & $17(2.9)$ & $9(4.6)$ & 0.255 \\
\hline $10-14$ & $249(31.9)$ & $217(37.1)$ & $32(16.3)$ & $<0.001$ \\
\hline $15-19$ & $256(32.8)$ & 204 (34.9) & $52(26.5)$ & 0.031 \\
\hline $20-24$ & 145 (18.6) & $92(15.7)$ & $53(27.0)$ & $<0.001$ \\
\hline $25-29$ & $79(10.1)$ & $47(8.0)$ & $32(16.3)$ & 0.001 \\
\hline Missing & $10(1.3)$ & $4(0.7)$ & $6(3.1)$ & 0.010 \\
\hline \multicolumn{5}{|l|}{ Living situation } \\
\hline On the street & $411(52.6)$ & $375(64.1)$ & $36(18.4)$ & $<0.001$ \\
\hline In a shelter/house & $308(39.4)$ & $170(29.1)$ & $138(70.4)$ & $<0.001$ \\
\hline Barracks/base & $35(4.5)$ & $29(5.0)$ & $6(3.1)$ & 0.267 \\
\hline Missing & $27(3.5)$ & $11(1.9)$ & $16(8.2)$ & $<0.001$ \\
\hline \multicolumn{5}{|l|}{ Living with ${ }^{\mathrm{a}}$} \\
\hline Parents & $66(8.5)$ & $32(5.5)$ & $34(17.4)$ & $<0.001$ \\
\hline Other family ${ }^{\mathrm{b}}$ & $40(5.1)$ & $16(2.7)$ & $24(12.2)$ & $<0.001$ \\
\hline Friends & $474(60.7)$ & $429(73.3)$ & $45(23.0)$ & $<0.001$ \\
\hline $\begin{array}{l}\text { Spouse, boyfriend, or } \\
\text { girlfriend }\end{array}$ & $88(11.3)$ & $31(5.3)$ & $57(29.1)$ & $<0.001$ \\
\hline Alone & $71(9.1)$ & $59(10.1)$ & $12(6.1)$ & 0.095 \\
\hline Other $^{\mathrm{c}}$ & $8(1.0)$ & $4(0.7)$ & $4(2.0)$ & 0.102 \\
\hline Missing & $38(4.9)$ & $16(2.7)$ & $22(11.2)$ & $<0.001$ \\
\hline
\end{tabular}

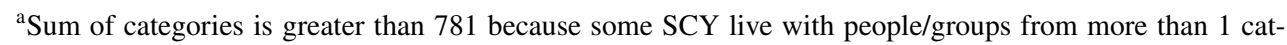
egory

${ }^{\mathrm{b}}$ Other family included siblings, grandparents, aunts, and uncles

${ }^{\mathrm{c}}$ Other living partners included single mothers and children 
the street or in rented houses with friends, whereas females predominantly spent their nights in a rented house either with a spouse/boyfriend, friends, or other family members. Only $8.5 \%$ of SCY reported living with parents, with females being almost three times more likely to do so than males.

\section{HIV Testing and Prevalence}

Table 2 presents the characteristics of HIV testing in the SCY engaged in the PN program. Just under half (47.8\%) of the SCY stated that they had tested for HIV before their first contact with the PNs. Of these, 21 males and 31 females $(3.6 \%$, vs. $15.8 \% \mathrm{p}<0.001)$ reported their HIV-positive status at the initial encounter. Consent to and uptake of HIV counselling and testing among the others at the initial encounter was very high $(88.8 \%, \mathrm{n}=647)$, though females were less likely than males to consent to testing $(80.0 \%$ vs. $91.3 \%, \mathrm{p}<0.001)$. Through testingat the initial encounter, 6 male and 6 female SCY $(1.1 \%$ vs. $3.6 \%$, p < 0.05$)$ were newly diagnosed HIV-positive.

Of the 781 SCY seen by PNs for an initial encounter, 152 (19.5\%) individuals who were HIV-negative at the initial PN encounter returned for at least one follow-up HIV test. The majority of returnees had either had an HIV test since their first visit or agreed to have one at the follow up visit. Three females who were seronegative at the initial encounter were found to be HIV-positive at follow-up. Of these, two tested positive through the follow-up PN encounter itself, and one had tested positive elsewhere. No males were found to be HIV-positive at follow-up. Four infants were recorded as being HIV-exposed at the initial PN visit. Two were subsequently found to have not seroconverted, and two had an uncertain HIV status. All four were excluded from further analysis.

Overall, 63 SCY (27 males and 36 females) were HIVpositive, bringing the prevalence of HIV in our sample to $8.1 \%$, with females being four times more likely to be HIVpositive than males $(18.4 \%$ vs. $4.6 \%$, p < 0.001$)$. At their initial and monthly encounters, HIV-positive SCY were asked 'whether you would like a PN to remind you to come to your next AMPATH appointment'. Individuals answered 'yes' to this question in 42 out of $60(70 \%)$ of initial and 187 out of $203(92.1 \%)$ monthly care encounters. Of the 36 HIV-positive females, two were pregnant at the initial PN encounter, and 20

Table 2 HIV testing

\begin{tabular}{|c|c|c|c|c|c|}
\hline Variable & & $\begin{array}{l}\text { Total } \\
\mathrm{N}=781\end{array}$ & $\begin{array}{l}\text { Male } \\
\mathrm{N}=585(74.9)\end{array}$ & $\begin{array}{l}\text { Female } \\
\mathrm{N}=196(25.1)\end{array}$ & $P$ value \\
\hline \multirow[t]{4}{*}{ Ever been tested for HIV } & Yes & $373(47.8)$ & $244(41.7)$ & $129(65.8)$ & $<0.001$ \\
\hline & No & $303(38.8)$ & $263(45.0)$ & $40(20.4)$ & $<0.001$ \\
\hline & Refuse to Answer & $92(11.8)$ & $75(12.8)$ & $17(8.7)$ & 0.119 \\
\hline & Missing & $13(1.7)$ & $3(0.5)$ & $10(5.1)$ & $<0.001$ \\
\hline \multirow[t]{4}{*}{ Status at initial encounter (self-stated) } & Positive & $52(6.7)$ & $21(3.6)$ & $31(15.8)$ & $<0.001$ \\
\hline & Negative & $313(40.1)$ & $217(37.1)$ & $96(49.0)$ & $<0.05$ \\
\hline & Don't know & $406(52.0)$ & $344(58.8)$ & $62(31.6)$ & $<0.001$ \\
\hline & Missing & $10(1.3)$ & $3(0.5)$ & $7(3.6)$ & 0.001 \\
\hline \multicolumn{6}{|c|}{ Tested for HIV with PNs if HIV status unknown or negative } \\
\hline \multirow[t]{2}{*}{ At initial PN encounter } & \# Tested $^{\mathrm{a}}$ & $647(88.8)$ & $515(91.3)$ & $132(80.0)$ & $<0.001$ \\
\hline & \# Newly HIV positive ${ }^{\mathrm{a}}$ & $12(1.7)$ & $6(1.1)$ & $6(3.6)$ & $<0.05$ \\
\hline \multirow[t]{2}{*}{ At follow up encounter } & \# Tested ${ }^{\mathrm{b}}$ & $128(84.2)$ & $94(83.2)$ & $34(87.2)$ & 0.555 \\
\hline & \# Newly HIV positive ${ }^{b}$ & $3(2.0)$ & 0 & $3(7.7)$ & $<0.005$ \\
\hline $\begin{array}{l}\text { Infants, seroconversion status uncertain or } \\
\text { negative - excluded from total HIV positive }\end{array}$ & & $4(0.5)$ & 0 & $4(2.0)$ & 0.001 \\
\hline \multirow[t]{6}{*}{ Total HIV positive } & All ages & $63(8.1)$ & $27(4.6)$ & $36(18.4)$ & $<0.001$ \\
\hline & Age $1-9$ & $7(0.9)$ & $4(0.7)$ & $3(1.5)$ & 0.276 \\
\hline & Age $10-14$ & $9(1.2)$ & $6(1.0)$ & $3(1.5)$ & 0.566 \\
\hline & Age $15-19$ & $10(1.3)$ & $4(0.7)$ & $6(3.1)$ & 0.010 \\
\hline & Age $20-24$ & $16(2.1)$ & $6(1.0)$ & $10(5.1)$ & 0.000 \\
\hline & Age $25-29$ & $21(2.7)$ & $7(1.2)$ & $14(7.1)$ & 0.000 \\
\hline Linked to care of those HIV positive ${ }^{c}$ & & $58(92.1)$ & $25(92.6)$ & $33(91.7)$ & 0.893 \\
\hline
\end{tabular}

${ }^{a} \mathrm{~N}=729$, the total number of people whose stated HIV status was negative or unknown. Individuals who disclosed HIV positive status at initial encounter are not included in counts for HIV testing

${ }^{\mathrm{b}} \mathrm{N}=152$, the total number of people who came for follow-up visits; 113 for males 39 for females

${ }^{\mathrm{c}} \mathrm{N}=63$, the total number of HIV positive SCY 
had ever been pregnant at least once. We were unable to assess whether vertical transmission of HIV took place in these cases.

\section{HIV Treatment: Linkage to Care, Uptake of ART, Retention in Care, and Viral Load Suppression}

Figure 1 summarizes the flow of the 781 SCY engaged in the PN program through the HIV care continuum. Of the 63 SCY who were HIV-positive, 25 (92.6\%) male SCY and 33 $(91.7 \%)$ female SCY, were linked-that is, had at least one clinical encounter with an HIV care provider at AMPATH. While the PNs were directly involved in linking 27/63 (43\%) HIV positive SCY to care, either for the first time or after previous loss to follow-up (LTFU), 31/63 (49\%) SCY encountered by the PN had already linked to care and 27 had initiated ART at some point. The SCY already linked to care were offered the same services as the SCY newly linked to care, specifically support in scheduling and attending followup visits. Figure 2 illustrates that SCY engaged by the PNs had a shorter time to initiation of ART after enrolling in care than those enrolled prior to the introduction of the PN program $(\mathrm{p}<0.001)$. Table 3 presents the care outcomes of the $58 \mathrm{SCY}$ who were HIV-positive and linked to care. As of October 2017, $48(82.8 \%)$ initiated ART, $35(60.3 \%)$ were still in care, 17 (29.3\%) were LTFU, and 6 (10.3\%) were deceased. Of those that were LTFU $(n=17)$, the median time to LTFU was 286.5 days (IQR 198.3-608.5). Of those who did not know their status prior to PN engagement, 15 were diagnosed HIV-positive. Of these, 12 were linked to care, of whom $9(75 \%)$ initiated ART, and $6(50 \%)$ were retained in care. Figure 1 and Table 3 describe ART initiation among SCY who were linked to care, and Fig. 3 shows the progress of SCY in the PN program toward achieving the UNAIDS 90-90-90 target [3].

As shown in Fig. 1, of the 48 HIV-positive SCY who had initiated ART, viral load measurements were available for 28 (58.3\%) individuals. Of these, 17 (60.7\%) had been virally suppressed at some point during their treatment. The median time to ever achieving viral suppression was 1.7 years (IQR 0.8-2.0). There was no significant difference in time to ART initiation, viral suppression, or lost to follow-up between males and females. As of October 2017, 35 of the 58 individuals living with HIV who had been linked to care were retained in care. However, out of the 26 individuals who had a viral load result and were still alive and in care, only 10 were virally suppressed.

\section{Discussion}

The key findings of this pilot to engage street connected youth in Eldoret, Kenya in HIV testing, treatment and care were as follows. Firstly, high numbers of SCY engaged with the PN and accepted HIV counselling and testing. Secondly, there was a high prevalence of HIV among SCY engaging with PNs, especially among female SCY. This is significantly higher than the background adult HIV prevalence in the region [9]. Finally, high numbers of HIV-positive SCY initiated treatment, linked to care, and were still in care as at the end of April 2017.

A number of factors likely contributed to the PN's success in engaging SCY in testing and linking them to care. The PNs were known and trusted by SCY, and reached out to $\mathrm{SCY}$ at the locations where they congregate and live. A large majority of the SCY engaged by the PNs accepted HIV testing, higher than national averages in adolescent populations in SSA [45]. This was potentially a result of the seamless transition from encounter to testing-immediately after the PN encounter, SCY who accepted HIV testing were escorted by a PN to the clinic. Whilst uptake of HIV testing was high among both genders, female SCY were less likely than male SCY to accept HIV testing. This is a serious concern, since HIV prevalence among females living on the street is higher than that among males. It is also worth noting that the majority of female HIV-positive SCY reported a current or previous pregnancy, which suggests that comprehensive and accessible reproductive care for $\mathrm{SCY}$ is critical to preventing vertical transmission of HIV.

The majority of SCY in this sample initiated ART, and time to ART initiation was significantly shorter for SCY who linked to care under the PN, although it is unclear whether this was caused by the PN program or due to a change in policy whereby all patients testing HIV-positive initiated ART regardless of CD4 count. Only a third of participants ever achieved viral load suppression despite relatively high rates of linkage to care or ART initiation. It was not possible to collect data on ART adherence directly, but this finding suggests that adherence to ART is a challenge in this population. The low rate of suppression may also be related to acquired or developed drug resistant viral mutations, causing a reduced response to ART. Systematic reviews measuring ART adherence among general adolescent populations in Africa have reported 81-84\% adherence [46, 47]. These rates are higher than those suggested here, reflecting the unique social and economic barriers to care faced by SCY. Youth with multiple barriers to care, including unmet mental health needs, homelessness, and poverty, have been shown to be less able to adhere to treatment [32]. They also may respond to these barriers in ways that negatively affect treatment outcomes-for example, not taking medication in order to conceal their HIV status from others. All these factors may be related to the low levels of viral suppression among SCY in Eldoret [32].

Although approximately half of our cohort were retained in care at the end of the reporting period, just under one third were LTFU. This may be related to instability in the 




* missing viral load data for 20 people

Fig. 1 The HIV care cascade for SCY engaging with PNs 


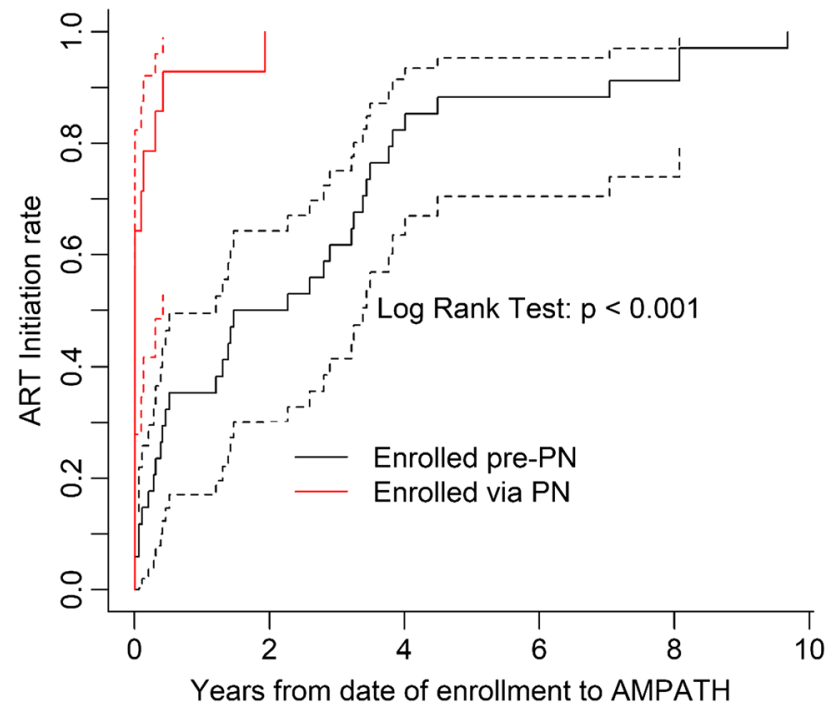

Fig. 2 Kaplan-Meier survival curve of time to ART start stratified by type of enrollment

population of SCY in Eldoret, or a variety of social and systemic barriers to retaining these young people in care. Prior research has shown that this population experiences a wide range of challenges, including poverty, high levels of transience, and stigma related to being street-involved [19, 20, 39, $48,49]$. SCY may not have regular meals or a place to store their ART, and are in danger of stigma and discrimination from the street community if found to be HIV-positive [20, $21,50]$. Once SCY leave the hospital grounds, it is difficult to contact them about follow-up visits as the vast majority do not own a mobile phone. Out of fear of police violence [15], many may also change their whereabouts frequently and thus could be difficult to locate. In order to increase adherence and retention, future research could work on identifying structural supports such as meals, access to communitybased and/or population-specific care, transport, and ART adherence supports.

Considering the high prevalence of HIV and the multifaceted barriers to HIV testing and treatment facing SCY, PNs may play a crucial role in containing the HIV epidemic among SCY in high HIV burden, low income settings. To the best of our knowledge, this is the first study to report outcomes of a peer engagement project with SCY in SSA to promote uptake of HIV testing, treatment, and care. Our results indicate that even though PNs were highly effective in linking SCY to testing and ART initiation, new strategies are needed to improve viral suppression. These results add to the systematic review carried out by Genberg et al., which found that peer interventions improved linkage and retention, but reported mixed effects on ART adherence and viral suppression [33]. Our cohort may have nearly achieved the first target of $90 \%$ of those living with HIV knowing their status, and is close to meeting the second target of the UNAIDS 90-90-90 framework, but more work is needed to achieve viral suppression in $90 \%$ of the population [3].

A strength of this study is that it was rooted in AMPATH, a large and well-established HIV program with strong links to HIV testing and care centres in a medium-sized city in a low-income setting. Secondly, this study focused on a particularly vulnerable and hard to reach population of adolescents and youth. This pilot contributes to the development and evaluation of evidence-based programs and interventions to address the burden of HIV in this high-risk community, especially among adolescent girls and young women. Finally, during the period of data collection for this study, a number of related initiatives took place which may have promoted contact between SCY and PNs or healthcare professionals, including the opening of the MTRH-Rafiki Center for Excellence in Adolescent Health (November 2016), a Point in Time count of SCY in Eldoret (September 2016) $[51$,$] and a voluntary male medical circumcision and$ educational 'coming-of-age' retreat for SCY (December 2016-May 2017) [52, 53.] These initiatives extended the program's reach in the SCY community and in connecting PNs to HIV-positive SCY looking to enter care. Limitations of this study include its reliance upon self-reported data recorded chiefly by the PN. We cannot rule out some selection bias if some SCY did not want to approach the PNs and thus were never included. Data quality also may have been limited by some inconsistencies in collection of data and low literacy levels in the target population. However, data quality did improve over time as the PNs built trust among SCY and became more experienced in data collection. As this study did not have a control group, it was only possible to measure uptake of the intervention rather than effectiveness. Furthermore, missing viral load data limited our ability to assess the impact of the PN program on viral suppression.

\section{Conclusion}

This pilot study suggests that PNs in this context appear to be feasible and potentially effective at promoting uptake of HIV counselling, testing, care and treatment. However, more research is needed to evaluate the optimal role of PNs in linkage and retention, and improve ART adherence in this population. Innovative, holistic programs may be necessary to address multifaceted barriers to long-term HIV treatment in the most vulnerable populations, potentially including targeted programs for SCY. 
Table 3 HIV treatment and care

\begin{tabular}{|c|c|c|c|c|c|c|c|c|c|}
\hline \multirow[t]{2}{*}{ Variable } & \multirow{2}{*}{$\begin{array}{l}\text { Total } \\
\mathrm{N}=58\end{array}$} & \multicolumn{4}{|c|}{ Linked to care prior to $\mathrm{PN}$ engagement } & \multicolumn{4}{|c|}{ New linked to care by PN } \\
\hline & & $\begin{array}{l}\text { Total } \\
\mathrm{N}=31\end{array}$ & $\begin{array}{l}\text { Male } \\
\mathrm{N}=13(41.9)\end{array}$ & $\begin{array}{l}\text { Female } \\
\mathrm{N}=18(58.1)\end{array}$ & $\mathrm{P}$ value & $\begin{array}{l}\text { Total } \\
N=27\end{array}$ & $\begin{array}{l}\text { Male } \\
\mathrm{N}=12(44.4)\end{array}$ & $\begin{array}{l}\text { Female } \\
\mathrm{N}=15(55.6)\end{array}$ & $\mathrm{P}$ value \\
\hline $\begin{array}{l}\text { Enrolled in } \\
\text { AMPATH } \\
\text { prior to } \\
\text { PN pro- } \\
\text { gram, and } \\
\text { remained } \\
\text { linked to } \\
\text { care during } \\
\text { PN program }\end{array}$ & $34(58.6)$ & & & & & & & & \\
\hline $\begin{array}{l}\text { On ART } \\
\text { prior to PN } \\
\text { program }^{\mathrm{a}}\end{array}$ & $27(79.4)$ & & & & & & & & \\
\hline $\begin{array}{l}\text { Lost to follow } \\
\text { up before } \\
\text { PN program } \\
\text { but recon- } \\
\text { nected via } \\
\text { PN }^{\mathrm{a}}\end{array}$ & $3(8.8)$ & & & & & & & & \\
\hline $\begin{array}{l}\text { Ever started } \\
\text { ART }\end{array}$ & $48(82.8)$ & $31(100.0)$ & $13(100.0)$ & $18(100.0)$ & & $17(63.0)$ & $7(58.3)$ & $10(66.7)$ & 0.706 \\
\hline $\begin{array}{l}\text { Time to ART } \\
\text { (years) }\end{array}$ & $0.5(0.1,3.2)$ & $2.3(0.4,3.6)$ & $1.4(0.1,3.3)$ & $3.1(0.7,3.7)$ & 0.109 & $\begin{array}{l}0.008(0.003 \\
0.312)\end{array}$ & $\begin{array}{l}0.101(0.003 \\
0.809)\end{array}$ & $\begin{array}{l}0.005(0.003 \\
0.265)\end{array}$ & 0.680 \\
\hline $\begin{array}{l}\text { Still in care } \\
\text { as of end } \\
\text { of October } \\
2017\end{array}$ & $35(60.3)$ & $23(74.2)$ & $10(76.9)$ & $13(72.2)$ & $>0.999$ & $12(44.4)$ & $6(50.0)$ & $6(40.0)$ & 0.707 \\
\hline $\begin{array}{l}\text { Time to loss } \\
\text { to follow-up } \\
\text { (days) }\end{array}$ & $\begin{array}{c}286.5(198.3, \\
608.5)\end{array}$ & $\begin{array}{l}286.5 \\
\quad(198.3 .0, \\
608.5)\end{array}$ & $\begin{array}{c}302.0(213.0 \\
604.0)\end{array}$ & $\begin{array}{l}271.0(182.0 \\
610.0)\end{array}$ & 0.739 & $\begin{array}{c}251.0(198.3 \\
482.8)\end{array}$ & $\begin{array}{l}261.3(211.3 \\
311.0)\end{array}$ & $\begin{array}{c}251.0(191.8 \\
623.5)\end{array}$ & $>0.999$ \\
\hline $\begin{array}{l}\text { Virally sup- } \\
\text { pressed at } \\
\text { the last visit } \\
\text { (among } \\
\text { those alive } \\
\text { and on } \\
\text { ART }^{\mathrm{b}}\end{array}$ & $10(38.5)$ & $4(20.0)$ & $2(20.0)$ & $2(20.0)$ & $>0.999$ & $6(100)$ & $2(100)$ & $4(100)$ & N/A \\
\hline $\begin{array}{l}\text { Missing viral } \\
\text { load data at } \\
\text { last visit }{ }^{\mathrm{c}}\end{array}$ & $20(41.7)$ & $7(25.9)$ & $0(0.0)$ & $7(41.2)$ & 0.026 & $4(40.0)$ & $3(60.0)$ & $1(20.0)$ & 0.229 \\
\hline
\end{tabular}

${ }^{\mathrm{a}} \mathrm{N}=34$, the total number of people who enrolled in AMPATH prior to the PN program and were still in care at some point during the PN program

${ }^{\mathrm{b}} \mathrm{N}=26$, the total number of people with viral load data who are still alive and in care (out of the total 48 who initiated ART, 20 are missing viral load data and 2 individuals with viral load data were LTFU at close of dataset)

${ }^{\mathrm{c}} \mathrm{N}=48$, the total number of people who initiated ART

Acknowledgements We wish to gratefully acknowledge the OSCAR staff and volunteers, whose enthusiasm for and commitment to the project have made this research possible. We would also like to thank the clinicians and staff in the AMPATH HIV clinics, in particular the Rafiki Adolescent clinic, for their time and effort in supporting street connected youth living with HIV.

Funding This research was funded by several sources including the Canadian Institutions of Health Research (CIHR) Institute of Public and Population Health, through an Applied Public Health Research Chair (2014-2019) to Dr. Braitstein, a CIHR Component 1 HIV Implementation Science Grant, funding Reference Number 145367. It was also supported by the American Association of Pediatrics through an I-CATCH Grant and the Lilly Foundation in its support of the 'FindLink-Treat-Retain' (FLTR) evaluation. This research is supported in part by by the President's Emergency Plan for AIDS Relief (PEPFAR) through USAID under the terms of Cooperative Agreement No. AID-623-A-12-0001 It is made possible through joint support of the United States Agency for International Development (USAID). The 


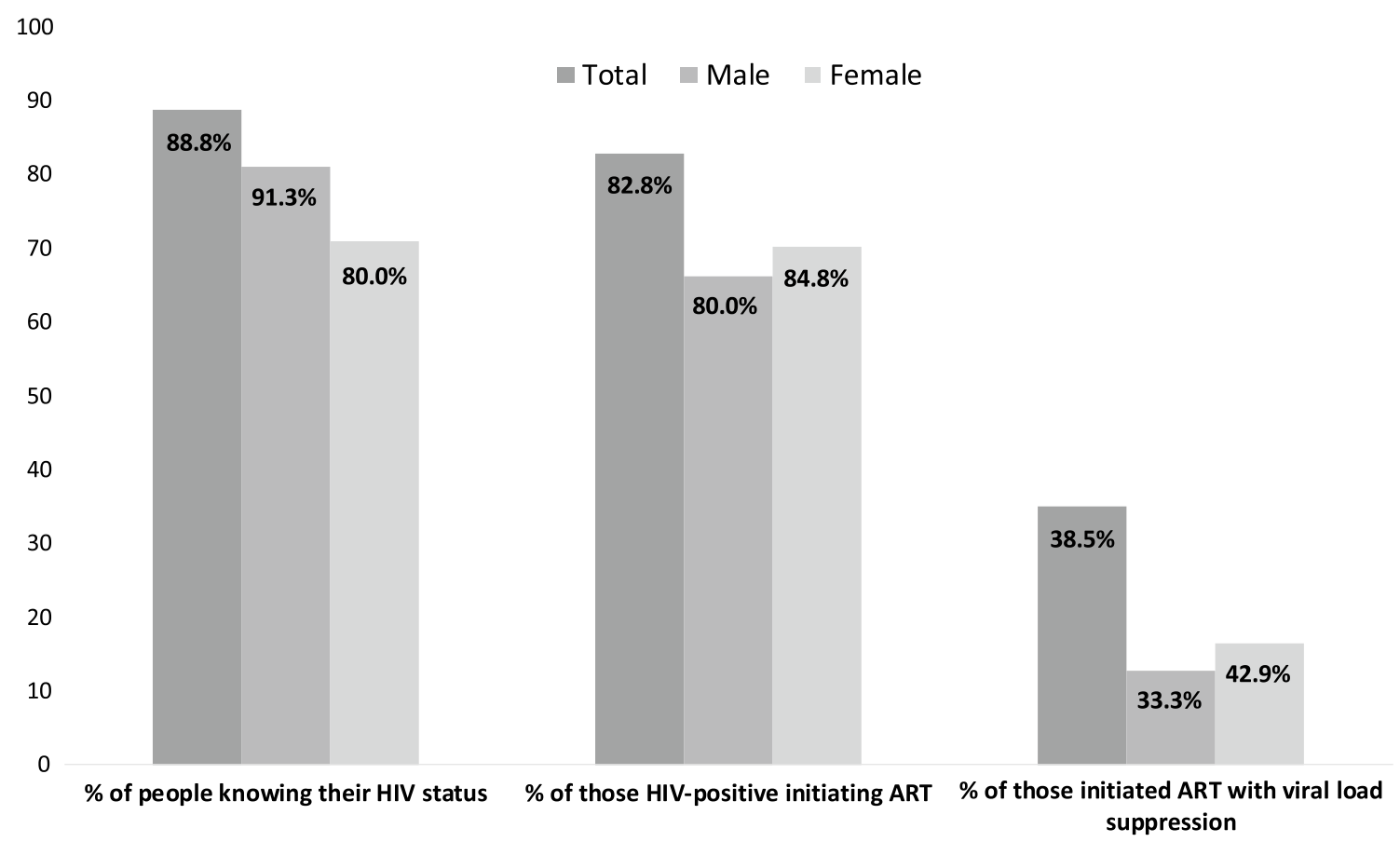

Fig. 3 Progress of SCY in PN program toward achieving UNAIDS 90-90-90 target

contents of this evaluation are the sole responsibility of the authors and do not necessarily reflect the views of USAID or the United States Government. We are also grateful for the support of the Eunice Kennedy Shriver National Institute of Child Health \& Human Development (R01HD060478). This content is solely the responsibility of the authors and does not necessarily represent the official views of the Eunice Kennedy Shriver National Institute of Child Health \& Human Development or the National Institutes of Health. Further funding was provided by Vanier Fellowship and IDRC PhD Research Grant to author L. Embleton, $\mathrm{PhD}$ (Cand) at the University of Toronto Institute of Medical Sciences.

\section{Compliance with Ethical Standards}

Conflicts of interest The authors have no conflicts of interest to disclose. All persons who made significant contributions to this study and the manuscript are included in the author list. The first draft of the manuscript was written by Pooja Shah, and no other honoraria, grants, or other forms of payment were given to anyone to produce the manuscript.

Research Involving Human and/or Animals Participants This is a research study involving human participants. The study population includes children, adolescents and youth aged up to 30 years old who, as per self-report, spend the majority of their days and nights on the street or with other street youth in a shared shelter. All procedures performed in studies involving human participants were in accordance with the ethical standards of the institutional and/or national research committee and with the 1964 Helsinki declaration and its later amendments or comparable ethical standards.

Informed Consent We sought and received institutional ethical approval to collect and disseminate de-identified data from Moi University/MTRH Institutional Research Ethics Committee, and the Uni- versity of Toronto Research Ethics Board, which included a waiver of written consent and assent.

Open Access This article is distributed under the terms of the Creative Commons Attribution 4.0 International License (http://creativeco mmons.org/licenses/by/4.0/), which permits unrestricted use, distribution, and reproduction in any medium, provided you give appropriate credit to the original author(s) and the source, provide a link to the Creative Commons license, and indicate if changes were made.

\section{References}

1. World Health Organization. HIV and Adolescents. Guidance for HIV testing and counselling and care for adolescents living with HIV. Geneva, Switzerland: WHO; 2013.

2. Joint United Nations Programme on HIV/AIDS. Global AIDS update 2016. Geneva: Switzerland; 2016.

3. Joint United Nations Programme on HIV/AIDS. 90-90-90: an ambitious treatment target to help end the AIDS epidemic. Geneva: UNAIDS; 2014.

4. UN Joint Programme on HIV/AIDS (UNAIDS). The gap report: UNAIDS; 2014. http://www.unaids.org/en/resources/campa igns/2014/2014gapreport/gapreport.

5. National AIDS Control Council. Kenya's fast-track plan to end HIV and AIDS among adolescents and young people. Nairobi: National AIDS Control Council; 2015.

6. Mark D, Armstrong A, Andrade C, Penazzato M, Hatane L, Taing L, et al. HIV treatment and care services for adolescents: a situational analysis of 218 facilities in 23 sub-Saharan African countries. J Int AIDS Soc. 2017;20(Suppl 3):25-33.

7. Ruria EC, Masaba R, Kose J, Woelk G, Mwangi E, Matu L, et al. Optimizing linkage to care and initiation and retention on 
treatment of adolescents with newly diagnosed HIV infection. AIDS. 2017;31:S253-60.

8. Government of Kenya, Ministry of Health. National Adolescent Sexual and Reproductive Health Policy. Nairobi: GoK; 2015.

9. Government of Kenya MoH. National AIDS Control Council, Kenya AIDS response progress report 2016. Nairobi: GoK; 2016.

10. Mitchell K, Nyakake M, Oling J. How effective are street youth peer educators? Lessons learned from an HIV/AIDS prevention programme in urban Uganda. Health Educ. 2007;107(4):364-76.

11. OHCHR. Protection and promotion of the rights of children working and/or living on the street2013 29 August 2016. http://www. streetchildrenresources.org/wp-content/uploads/2013/07/OHCHR -protection-promotion.pdf.

12. Goldblatt A, Kwena Z, Lahiff M, Agot K, Minnis A, Prata N, et al. Prevalence and correlates of HIV infection among street boys in Kisumu, Kenya. PLoS ONE. 2015;10(10):e0140005.

13. Winston SE, Chirchir AK, Muthoni LN, Ayuku D, Koech J, Nyandiko W, et al. Prevalence of sexually transmitted infections including HIV in street-connected adolescents in western Kenya. Sex Transm Infect. 2015;91(5):353-9.

14. Embleton L, Makori D., Kamanda A., Ayuku D., Braitstein P. Causes of death among street-connected children and youth in Eldoret, Kenya. Under review.

15. Blomfield A. How raid by Kenyan police drove street children to their deaths. The Guardian. 2016 Monday, October 102016.

16. Embleton L, Mwangi A, Vreeman R, Ayuku D, Braitstein P. The epidemiology of substance use among street children in resourceconstrained settings: a systematic review and meta-analysis. Addiction. 2013;108(10):1722-33.

17. Embleton L, Wachira J, Kamanda A, Naanyu V, Ayuku D, Braitstein P. Eating sweets without the wrapper: perceptions of HIV and sexually transmitted infections among street youth in western Kenya. Cult Health Sex. 2015;18(3):337-48.

18. Embleton L, Wachira J, Kamanda A, Naanyu V, Winston S, Ayuku $\mathrm{D}$, et al. "Once you join the streets you will have to do it": sexual practices of street children and youth in Uasin Gishu County, Kenya. Reprod Health. 2015;12:106.

19. Sorber R, Winston S, Koech J, Ayuku D, Hu L, Hogan J, et al. Social and economic characteristics of street youth by gender and level of street involvement in Eldoret, Kenya. PLoS ONE. 2014;9(5):e97587.

20. Wachira J, Kamanda A, Embleton L, Naanyu V, Ayuku D, Braitstein P. 'Pregnancy has its advantages': the voices of street connected children and youth in Eldoret, Kenya. PLoS ONE. 2016;11(3):e0150814

21. Wachira J, Kamanda A, Embleton L, Naanyu V, Winston S, Ayuku D, et al. Initiation to street life: a qualitative examination of the physical, social, and psychological practices in becoming an accepted member of the street youth community in Western Kenya. BMC Public Health. 2015;15(1):1.

22. Kaime-Atterhög W, Lindmark G, Persson L-Å, Ahlberg BM. Burning "Centre Bolt": experiences of sexually transmitted infections and health care seeking behaviour described by street boys in Urban Kenya. Child Youth Serv Rev. 2007;29(5):600-17.

23. Kayembe PK, Mapatano MA, Fatuma AB, Nyandwe JK, Mayala GM, Kokolomami JI, et al. Knowledge of HIV, sexual behaviour and correlates of risky sex among street children in Kinshasa, Democratic Republic of Congo. East Afr J Public Health. 2008;5(3):186-92.

24. Lockhart C. Kunyenga," real sex," and survival: assessing the risk of HIV infection among urban street boys in Tanzania. Med Anthropol Q. 2002;16(3):294-311.

25. Mandalazi P, Banda C, Umar E. Street children's vulnerability to HIV and sexually transmitted infections in Malawian cities. Malawi Med J. 2013;25(1):1-4.
26. Nada KH, El Daw AS. Violence, abuse, alcohol and drug use, and sexual behaviors in street children of Greater Cairo and Alexandria, Egypt. AIDS. 2010;24:S39-44.

27. Wutoh AK, Kumoji EK, Xue Z, Campusano G, Wutoh RD, Ofosu JR. HIV knowledge and sexual risk behaviors of street children in Takoradi, Ghana. AIDS Behav. 2006;10(2):209-15.

28. Swahn MH, Culbreth R, Salazar LF, Kasirye R, Seeley J. Prevalence of HIV and associated risks of sex work among youth in the slums of Kampala. AIDS research and treatment. 2016;2016.

29. Tadesse N, Awoke Ayele T, Birhanu Mengesha Z, Addis Alene K. High prevalence of HIV/AIDS risky sexual behaviors among street youth in Gondar town: a community based cross sectional study. BMC Res Not. 2013;6:234.

30. Tyler KA, Handema R, Schmitz RM, Phiri F, Wood C, Olson K. Risk factors for HIV among Zambian street youth. J HIV/AIDS Soc Serv. 2016;15(3):254-68.

31. Cumber SN, Tsoka-Gwegweni JM. The health profile of street children in Africa: a literature review. J Public Health Afr. 2015;6(2):566.

32. Lall P, Lim SH, Khairuddin N, Kamarulzaman A. An urgent need for research on factors impacting adherence to and retention in care among HIV-positive youth and adolescents from key populations. J Int AIDS Soc. 2015;18(2Suppl 1):19393.

33. Genberg BL, Shangani S, Sabatino K, Rachlis B, Wachira J, Braitstein P, Operario D. Improving engagement in the HIV care cascade: a systematic review of interventions involving people living with HIV/AIDS as peers. AIDS Behav. 2016;20:2452-63.

34. Okeke NL, Ostermann J, Thielman NM. Enhancing linkage and retention in HIV care: a review of interventions for highly resourced and resource-poor settings. Curr HIV/AIDS Rep. 2014;11(4):376-92.

35. Bradford JB, Coleman S, Cunningham W. HIV system navigation: an emerging model to improve HIV care access. AIDS Patient Care STDS. 2007;21(Suppl 1):S49-58.

36. Uasin Gishu County Government. Welcome to the county of champions. 201229 August 2016. http://uasingishu.go.ke/.

37. Commision on Revenue Allocation. Kenya County fact sheets: Uasin Gishu County. Nairobi: Commision on Revenue Allocation, Government of Kenya; 2011.

38. Einterz R, Kimaiyo HNKM, Khwa-Otsyula BO, Esamai F, Quigley $\mathrm{F}$, et al. Responding to the HIV pandemic: the power of an Academic Medical Partnership. Acad Med. 2007;82:812-8.

39. Wools-Kaloustian K, Kimaiyo S, Musick B, et al. The impact of the President's Emergency Plan for AIDS relief on expansion of HIV care services for adult patients in western Kenya. 2009;23(2):195-201.

40. Naanyu V, Sidle JE, Frankel RM, Ayuku D, Nyandiko WM, Inui TS. Rooting inquiry in tradition: the health baraza as a tool for social research in Kenya. Qual Health Res. 2011;21(1):14-26.

41. Kamanda A, Embleton L, Ayuku D, Atwoli L, Gisore P, Ayaya $S$, et al. Harnessing the power of the grassroots to conduct public health research in sub-Saharan Africa: a case study from western Kenya in the adaptation of community-based participatory research (CBPR) approaches. BMC Public Health. 2013;13(1):91.

42. Embleton L, Ott MA, Wachira J, Naanyu V, Kamanda A, Makori $\mathrm{D}$, et al. Adapting ethical guidelines for adolescent health research to street-connected children and youth in low-and middle-income countries: a case study from western Kenya. BMC Med Ethics. 2016;16(1): 1

43. UNESCO. What do we mean by "youth"? 2017. http://www.unesc o.org/new/en/social-and-human-sciences/themes/youth/youth -definition/.

44. Ministry of Youth Affairs. Kenya National Youth Policy 2006. http://www.youthpolicy.org/national/Kenya_2006_National_ Youth_Policy.pdf. 
45. Sam-Agudu NA, Folayan MO, Ezeanolue EE. Seeking wider access to HIV testing for adolescents in sub-Saharan Africa. Pediatr Res. 2016;79(6):838-45.

46. Kim S-H, Gerver SM, Fidler S, Ward H. Adherence to antiretroviral therapy in adolescents living with HIV: systematic review and meta-analysis. AIDS. 2014;28(13):1945-56.

47. Zanoni BC, Archary M, Buchan S, Katz IT, Haberer JE. Systematic review and meta-analysis of the adolescent HIV continuum of care in South Africa: the Cresting Wave. BMJ Glob Health. 2016;1(3):e000004.

48. Asante KO. Street children and adolescents in Ghana: a qualitative study of trajectory and behavioural experiences of homelessness. Glob Soc Welf. 2016;3(1):33-43.

49. Coren E, Hossain R, Pardo J, Veras M, Chakraborty K, Harris $\mathrm{H}$, et al. Interventions for promoting reintegration and reducing harmful behaviour and lifestyles in street-connected children and young people. Evid Based Child Health. 2013;8(4):1140-272.

50. Wolf HT, Halpern-Felsher BL, Bukusi EA, Agot KE, Cohen CR, Auerswald CL. "It is all about the fear of being discriminated [against]... the person suffering from HIV will not be accepted": a qualitative study exploring the reasons for loss to follow-up among HIV-positive youth in Kisumu, Kenya. BMC Public Health. 2014;14(1):1154.

51. Braitstein P, Ayuku D, Makori D, Sang E, DeLong A, Shah P, et al. A point-in-time count and population HIV prevalence among street-connected children, youth, and adults in a mid-sized city of western Kenya. Under review.

52. Kibel M, Shah P, Ayuku D, Makori D, Kamaara E, Choge E, Nyairo J, Abuyae P, Wahome M, Wachira J, Braitstein P. Acceptability of a pilot intervention of voluntary medical male circumcision and HIV education for street-connected youth in western Kenya. J Adolesc Health (in press).

53. Ochieng D, Choge I, Rotich EC, Maritim B, Bernheimer I, Geng E, et al. Evaluating the outcomes of patients lost to follow-up from a large HIV treatment program in western Kenya. Washington, DC: International AIDS Society; 2012. 